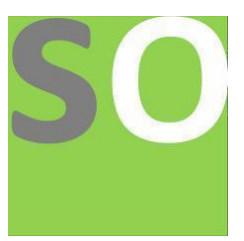

Article title: A Techno-economic Evaluation of Adding Silica Nanoparticles to Enhance the Demulsification Process in a Crude Oil Central Processing Facility

Authors: Shireen Hassan[1], Babiker Abdalla[2], Mustafa Mustafa[3]

Affiliations: Chemical Engineering Department, Faculty of Engineering, University of Khartoum, Sudan[1], Chemical Engineering, Karari University. Sudan[2]

Orcid ids: 0000-0003-2385-2022[3]

Contact e-mail: dr.mustafa.abbas@gmail.com

License information: This work has been published open access under Creative Commons Attribution License http://creativecommons.org/licenses/by/4.0/, which permits unrestricted use, distribution, and reproduction in any medium, provided the original work is properly cited. Conditions, terms of use and publishing policy can be found at https://www.scienceopen.com/.

Preprint statement: This article is a preprint and has not been peer-reviewed, under consideration and submitted to ScienceOpen Preprints for open peer review.

Funder: Sudanese Ministry of Higher Education and Scientific Research

DOI: 10.14293/S2199-1006.1.SOR-.PPZJNVW.v1

Preprint first posted online: 26 May 2021

Keywords: Techno-economics, Demulsification, Nanoparticles 


\title{
A Techno-economic Evaluation of Adding Silica Nanoparticles to Enhance the Demulsification Process in a Crude Oil Central Processing Facility
}

\author{
Shireen A. Hassan a , Babiker K. Abdalla ${ }^{\mathrm{b}}$, and Mustafa A. Mustafa ${ }^{\mathrm{c}, *}$ \\ ${ }^{a}$ Department of Chemical Engineering, Faculty of Engineering, University of Khartoum, Khartoum, Sudan \\ ${ }^{b}$ Chemical Engineering, Karari University, Khartoum, Sudan \\ ${ }^{c}$ Materials and Nanotechnology Research Centre, Faculty of Engineering, University of Khartoum, Khartoum, Sudan
}

\begin{abstract}
In this study, a techno-economic evaluation of the use of silica nanoparticles to enhance the demulsification process, in crude oil, has been investigated. A software model has been developed in MS Excel of the central processing facility (CPF). A sensitivity analysis of key parameters on production cost and Net Present Value (NPV) has been carried out for different flowsheet selection options. Comparison of flowsheets on an equal plant capacity basis results in a $19 \%$ reduction in the production cost whereas comparison on a fixed annual crude oil processing basis results in a reduction in production cost of only $3.7 \%$.
\end{abstract}

Keywords: Techno-economics, Demulsification, Nanoparticles

\section{INTRODUCTION}

Removing produced water from the crude oil is a crucial as it may cause many technical problems like dripping and corrosion of pipes (Kokal, 2005). Also, it is important for the crude oil to meet the required international specifications prior to export. Produced water mixes with the crude oil in two ways, as free water which settles down rapidly by gravity in sedimentation tanks and as emulsion which disperse in the form of droplets in the oil phase. Many studies have been conducted to improve the demulsification process in an efficient and rapid manner. One of which is based on the addition of silica nano-particles, to commonly used chemical demulsifier, to enhance its effectivesness in removing the emulsion (Gandomkar et al.(2016), Hassan et al. (2019)). Hassan et al. (2019) showed good progress where both a $159 \%$ increase in the percentage of water removal and acceleration of the demulsification process was achieved. The addition of the silicananoparticles requires only an ultrasonic homogenizer unit to disperse the powder in water and form a stable and uniform suspension at a concentration of $60 \mathrm{ppm}$. The suspension should be injected into the crude oil inlet header and raw crude manifold simultaneously with the chemical demulsifier at a ratio 1:0.5 for demulsifier to nano-particle suspension. The technical feasibility of this method encouraged the work of this study to investigate its economic feasibility by performing a thorough techno-economic analysis. 


\section{MATERIALS AND METHODS}

\section{Model components}

The CPF is assumed to consist of heavy crude manifold, sand trap, two heat exchangers and 30\% of the crude is also heated by the vis-broken hot oil in another two heat exchangers to the temperature of $75^{\circ} \mathrm{C}$. The heated crude oil is then sent to the degas pipes where the free gas will be vent from the top of the pipes. Oil and water from the degas pipes are sent to first stage sedimentation tanks and then to second stage sedimentation tanks where the oil and water are separated by gravity and chemical demulsifiers. The water cut of the separated crude should be less than $0.5 \%$. The dehydrated crude then enters the surge tanks and is pumped through five transfer pumps to the shipping tanks and by other three centrifugal pumps to the metering skid (figure 1). The assumptions for the developed model are shown in table 1.

\section{Capital Cost of the CPF Model}

The capital and operating costs of the CPF plant were calculated based on the estimated costs of the main equipment of the plant. The heat exchangers, sedimentation tanks and the surge tanks costs were estimated from the correlation (Towler and Sinnott, 2009):

$$
\mathrm{C}_{\mathrm{e}}=\mathrm{a}+\mathrm{b} S^{n}
$$

Where $C_{e}$ is purchased equipment cost, $\mathrm{S}$ is characteristic size parameter, $\mathrm{a}$ and $\mathrm{b}$ are the cost constants and $\mathrm{n}$ is the index for that type of equipment.

The shipping tanks cost is estimated from (Milligan, 2019). Data for the rest of the equipment were obtained from the historical prices of an existing CPF plant. All of the costs were updated to 2019 by using the cost escalation method. Also, a location factor of 2 was used to adjust the prices. The fixed capital cost was estimated by using the factorial method (Towler and Sinnott, 2009). The fixed capital cost is given as a function of the total purchase equipment cost by the equation:

$$
\mathrm{C}_{\mathrm{f}}=4.7 \sum \mathrm{C}_{\mathrm{e}}
$$

Where: $C_{\mathrm{f}}=$ fixed capital cost, $\mathrm{C}_{\mathrm{e}}=$ the total delivered cost of all the major equipment items like storage tanks and heat exchangers and the constant number is Lang factor in a fluid plant.

The working capital was taken as $15 \%$ of the fixed capital. The total investment was calculated as the sum of the two costs see table 2 . 
Table 1: Base case assumptions for the CPF

\begin{tabular}{ll}
\hline Information & Value \\
\hline Feed flow rate of crude oil (BOPD) & 50,000 \\
\hline Percentage of water in feed & $70 \%$ \\
\hline GOR & 3.5 \\
\hline Lang factor & 4.74 \\
\hline No. Of operating days $(\mathrm{d} / \mathrm{y})$ & 365 \\
\hline Price of crude oil $(\$ / \mathrm{bbl})$ & 60 \\
\hline Percentage of crude heated by vis-broken hot oil & $30 \%$ \\
\hline Project life (years) & 30 \\
\hline Demulsifier concentration $(\mathrm{ppm})$ & 50 \\
\hline Unit price of demulsifier $(\$ / \mathrm{l})$ & 4.5 \\
\hline Price of nanoparticles $(\$ / \mathrm{kg})$ & 1,600 \\
\hline Interest rate & $12 \%$ \\
\hline
\end{tabular}

Table 2: Capital cost estimation

\begin{tabular}{|c|c|c|c|c|c|c|}
\hline Equipment & $\begin{array}{l}\text { no. of } \\
\text { units }\end{array}$ & Capacity & $\begin{array}{l}\text { Cost } \\
\text { base }\end{array}$ & $\begin{array}{l}\text { Cost } \\
\text { \$/unit }\end{array}$ & $\begin{array}{l}\text { Updated } \\
\text { cost (2019) } \\
\text { \$/unit }\end{array}$ & Yield (\$) \\
\hline Heat Exchanger & 4 & $6.12 \mathrm{MW}$ & 2007 & 500,000 & 611,162 & $2,444,646$ \\
\hline $\begin{array}{l}\text { Sedimentation } \\
\text { Tank }\end{array}$ & 4 & $5000 \mathrm{~m}^{3}$ & 2007 & $2,000,000$ & $2,444,646$ & $9,778,584$ \\
\hline Surge Tank & 2 & $1000 \mathrm{~m}^{3}$ & 2007 & 950,000 & $1,161,207$ & $2,322,414$ \\
\hline Sand Trap & 1 & _- & 1998 & 245,000 & 413,294 & 413,294 \\
\hline $\begin{array}{l}\text { Gas Boot (De-gas } \\
\text { pipe) }\end{array}$ & 2 & - & 1998 & 350,000 & 590,420 & $1,180,839$ \\
\hline Transfer Pumps & 9 & 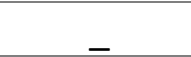 & 1998 & 760,000 & $1,282,054$ & $11,538,485$ \\
\hline Metering System & 3 & $\begin{array}{l}60,000 \\
\text { BOPD }\end{array}$ & 1998 & $2,500,000$ & $4,217,282$ & $12,651,847$ \\
\hline Shipping Tank & 5 & $20000 \mathrm{~m}^{3}$ & 2014 & $4,000,000$ & $4,038,981$ & $20,194,903$ \\
\hline $\begin{array}{l}\text { Total equipment } \\
\text { cost }\end{array}$ & & & & & & $60,525,011$ \\
\hline Fixed capital & & & & & & $286,888,554$ \\
\hline Working capital & & & & & & $43,033,283$ \\
\hline Total investment & & & & & & $329,921,837$ \\
\hline
\end{tabular}

\section{Production Cost Calculation}

The operating cost is divided into fixed and variable costs. The fixed cost consists of the operating labour, supervision, direct salary overhead, the maintenance, taxes and insurance, rent of land and general plant overhead. The variable cost in this case consists of the utilities, consumables and the chemical demulsifier is put separated from the utilities. The sales expenses, general overheads and R\&D costs are grouped as indirect costs and taken as $30 \%$ of the direct production cost (fixed and variable) see table 3 . The addition of the silica nanoparticles requires an ultrasonic homogenizer (probe sonicator) with a high capacity recirculating chiller. The estimated cost for the addition of 
this unit is shown $\$ 11,000$. The price of the silica nanoparticles is set at $\$ 1,600$ per $\mathrm{kg}$. Hassan et al. (2019), shows how the use of silica nanoparticles results in an average reduction in treatment time of $24 \%$.

Table 3: Operating cost estimation

\begin{tabular}{lc}
\hline \multicolumn{1}{c}{ Variable cost } & Cost (\$) \\
\hline Demulsifier & 665,264 \\
\hline Consumables $\quad$ Fixed cost & $1,434,703$ \\
\hline Utilities & $9,581,053$ \\
\hline Sub Total & $\mathbf{1 1 , 8 2 4 , 4 5 5}$ \\
\hline & \\
\hline Maintenance & $14,347,035$ \\
\hline Operating Labour & 480,000 \\
\hline Supervision & 96,000 \\
\hline Plant overheads & $\mathbf{2 4 0 , 0 0 0}$ \\
\hline Laboratory & $\mathbf{1 4 4 , 0 0 0}$ \\
\hline Capital charges & $9,564,690$ \\
\hline Insurance & $2,869,407$ \\
\hline Local taxes & $5,738,814$ \\
\hline Sub Total & $\mathbf{3 3 , 4 7 9 , 9 4 5}$ \\
\hline Direct Production costs & $45,304,400$ \\
\hline Indirect cost & $13,591,320$ \\
\hline Annual Production cost & $58,706,874$ \\
\hline Production cost (\$/bbl) & $\mathbf{3 . 2}$ \\
\hline
\end{tabular}




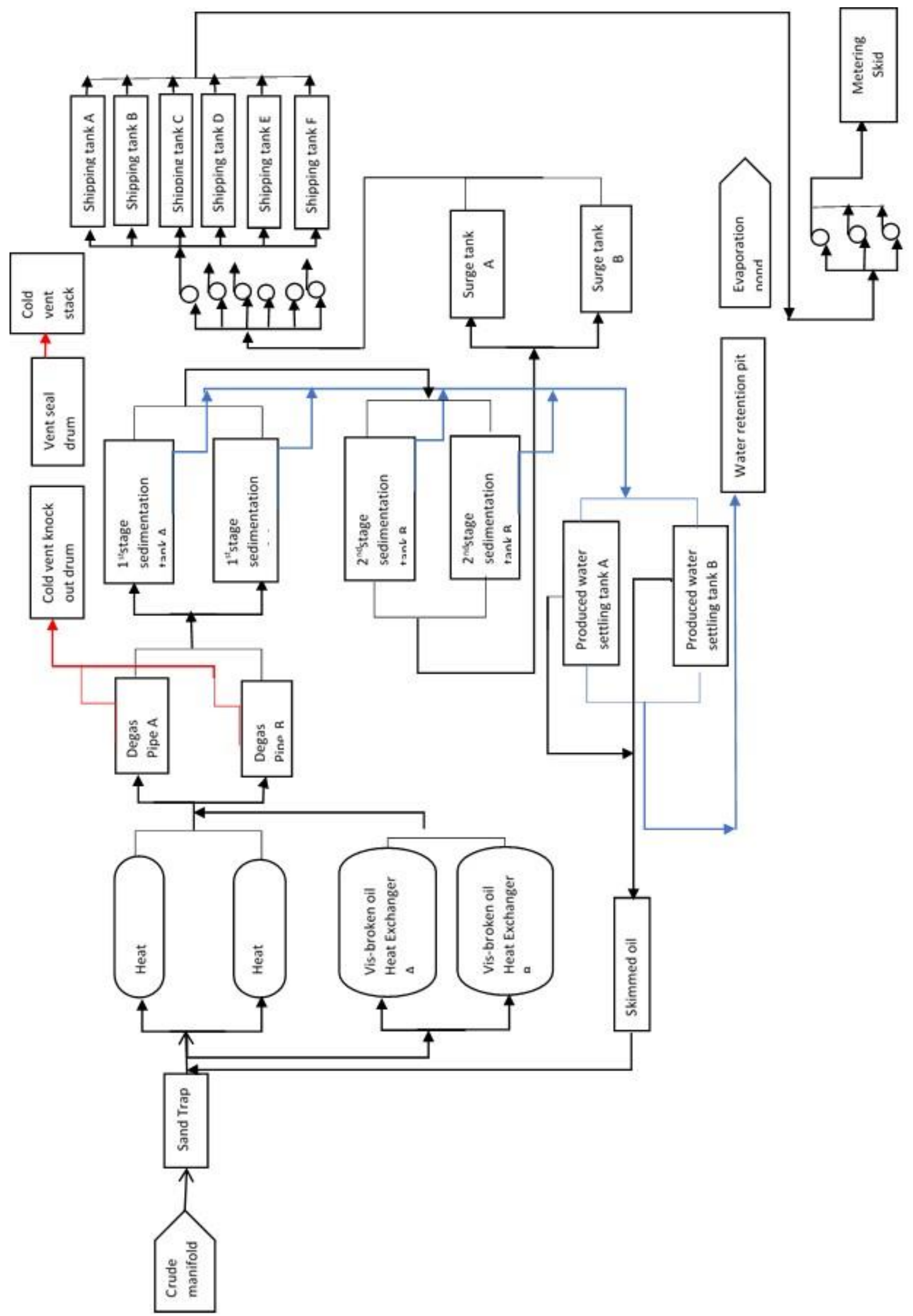

Fig.1: Flow diagram of Central Processing Facility 


\section{NPV calculations}

The cash flow was estimated and NPV was calculated. A lifetime of 30 years was assumed for the CPF. The interest rate was taken as $12 \%$ as shown in table 1 . The flow rate of the crude oil was assumed to be $40,000 \mathrm{bbl} / \mathrm{d}$ in the first six years and increased to $50,000 \mathrm{bbl} / \mathrm{d}$ afterwards. The net production of the crude is calculated after the removal of water and gas. The assumed price of the crude oil was taken as $60 \$ / \mathrm{bbl}$. Investment is based on the fixed and working capitals in the first two years. The net cash flow is calculated by subtracting the operating cost and the investment from the income. The total net present value of was calculated from the net cash flow i.e. net future value by using the following formula (Towler and Sinnott, 2009)

$$
N P V=\sum_{n=1}^{n=t} \frac{N C F}{(1+r)^{n}}
$$

Where NPV is the total net present value, NCF is the net future value, $r$ is the interest rate, $n$ is the year and $t$ is the assumed project life.

\section{Sensitivity Analysis}

The variation impact of $\pm 35 \%$ of some parameters on the NPV and the production cost was studied. The varying parameters include crude oil prices, feed flow rate of crude oil (barrels per day), varying concentration of proposed silica nanoparticles (ppm) and prices of silica nanoparticles.

\section{Flowsheet Selection Options}

Two flowsheets were proposed: A traditional CPF and a CPF where a sonicator was added to introduce the silica nanoparticles. The flowsheets were compared based on an equal plant capacity or on a fixed annual crude oil processing basis. In case of the similar plant capacity, the facility that uses silica nanoparticles was modified to be able to treat a higher feed flow rate. On the other hand, when the same feed flow rate is considered for both flowsheets, the sedimentation tanks

were resized to reflect the added benefit of reduction in sedimentation time provided with the use of silica nanoparticles.

\section{RESULTS AND DISCUSSION}

\section{CPF capital and operating cost}

The calculations for the capital and operating costs of the CPF plant are shown in tables 2 and 3. Table 4 shows the utilities cost breakdown. 
Table 4: Utilities cost breakdown

\begin{tabular}{|c|c|c|c|c|c|c|}
\hline Utility & $\begin{array}{l}\text { Estimated } \\
\text { Cost }\end{array}$ & $\begin{array}{l}\text { Updated } \\
\text { price } \\
(2019)\end{array}$ & $\begin{array}{l}\text { Required } \\
\text { amount }\end{array}$ & Units & $\begin{array}{l}\text { Quantity } \\
\text { per year }\end{array}$ & $\begin{array}{l}\text { Total cost } \\
\text { \$/ year }\end{array}$ \\
\hline Process water $(\$ / t)$ & 0.3 & 0.4 & 18 & $\mathrm{~m}^{3} / \mathrm{h}$ & 157,680 & 63,765 \\
\hline $\begin{array}{l}\text { Compressed air } \\
\left(\mathrm{c} / \mathrm{m}^{3}\right)\end{array}$ & 0.6 & 0.8 & 120 & $\mathrm{~m}^{3} / \mathrm{h}$ & $1,051,200$ & 850,203 \\
\hline Fuel oil $(\$ / t)$ & 100 & 134.8 & 992,712 & $\mathrm{MJ} / \mathrm{d}$ & $362,340,048$ & $8,654,343$ \\
\hline $\begin{array}{l}\text { Waste water } \\
\text { treatment }(\$ / t)\end{array}$ & 1.3 & 1.5 & 5,573 & $\mathrm{~m}^{3} / \mathrm{d}$ & 8,427 & 12,741 \\
\hline Total utilities & & & & & & $9,581,053$ \\
\hline
\end{tabular}

Effect of varying key factors on NPV

Figure 2 shows the effect of $\pm 35 \%$ change in some key factors on the NPV. From the figure NPV is sensitive to change in crude oil prices. $\mathrm{A} \pm 35 \%$ change in the crude oil prices would cause more than $\pm 40 \%$ change in NPV. All relations show linearity in their positive and negative change. The second factor that has a great influence on the NPV is the feed flow rate.

Effect of varying some factors on the production cost

The production cost also has direct relation with the feed flow rate of the crude oil. On the other hand, the change in the nanoparticles prices or concentration has negligible effect on the production cost and the NPV.

Cost of adding silica nanoparticles

The financial study shows negligible effect of the overall cost of adding silica nanoparticles on the NPV and the production cost. This is due to its small contribution when compared to the other major components. 


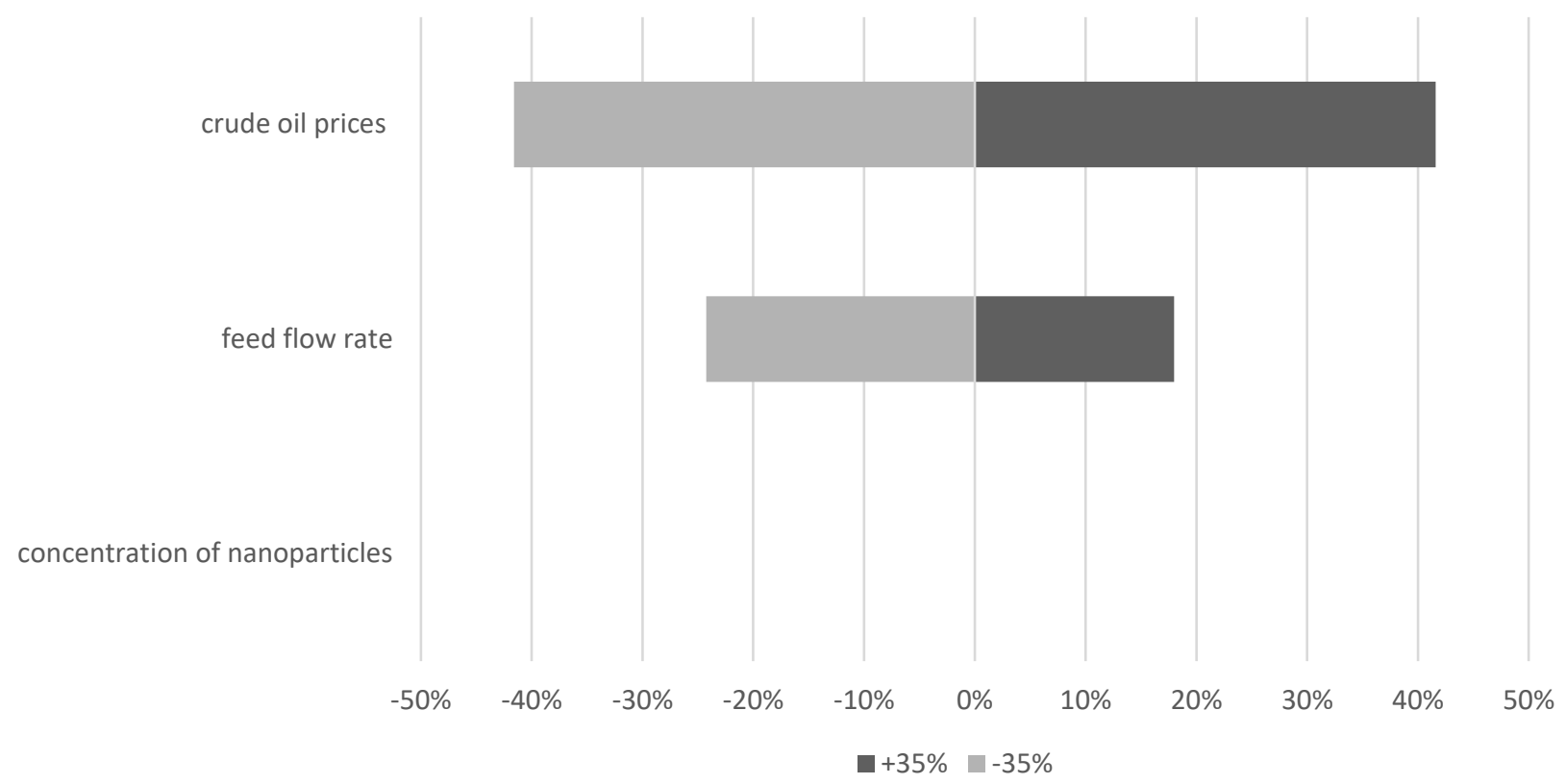

Fig 2: Effect of change in crude oil prices, feed flow rate and concentration of nanoparticles on NPV.

Financial impact of adding silica nanoparticles

First flowsheet option: Same plant capacity basis

As mentioned earlier the required time for demulsification is reduced by $24 \%$ when silica nanoparticles are added. For the same plant capacity adding silica nanoparticles may serve in reducing the required time inside the sedimentation tanks which will allow for processing more crude oil. The impact of processing more crude i.e. increasing the feed flow rate directly affects the production cost by decreasing it by 19\% as shown in Table 5 .

Second flowsheet option: Same feed flow rate basis

In the case of adding silica nanoparticles to a CPF, which handles the same flow rate, the acceleration in the demulsification process may serve in reducing the required sedimentation tank capacity. Table 6 show the effect of this adjustment on the total estimated investment and accordingly on the production cost. 
Table 5: Effect of reducing the retention time on the increasing the feed flow rate and on the production cost

\begin{tabular}{lcc}
\hline Retention time percentage decrease & Base case & $\begin{array}{c}\text { Case with } \\
\text { nanoparticles }\end{array}$ \\
\hline Flow rate $(\mathrm{bbl} / \mathrm{d})$ & 50,000 & 65,789 \\
\hline Production cost $(\$ / \mathrm{bbl})$ & 3.3 & 2.6 \\
\hline $\begin{array}{l}\text { Percentage change in } \\
\text { production cost }(\%)\end{array}$ & & $-19.0 \%$ \\
\hline
\end{tabular}

Table 6: Effect of reducing the retention time on reducing the required capacity of the sedimentation tanks and the production cost

\begin{tabular}{lcc}
\hline & Base case & $\begin{array}{c}\text { Case with } \\
\text { nanoparticles }\end{array}$ \\
\hline Settling time in sedimentation tank (hours) & 8 & 6 \\
\hline Required capacity of sedimentation tank $\left(\mathrm{m}^{3}\right)$ & 5000 & 3800 \\
\hline Cost of equipment $(\$)$ & $2,000,000$ & $1,382,632$ \\
\hline Total investment million $(\$)$ & $329,981,798$ & $313,527,992$ \\
\hline Production cost $(\$ / \mathrm{bbl})$ & 3.2 & 3.1 \\
\hline Percentage change in & & \\
production cost $(\%)$ & & $3.7 \%$ \\
\hline
\end{tabular}

\section{CONCLUSION}

A techno-economic analysis was conducted for the use of silica nanoparticles in a CPF processing Fula heavy crude oil (Balila, Sudan). The study showed that the NPV is sensitive to change in crude oil prices and feed flow rate. It showed also that the feed flow rate highly affects the production cost. The overall cost of adding silica nanoparticles does not have a tangible effect on NPV neither on production cost. Flowsheet selection on an equal plant capacity basis results in a $19 \%$ reduction in the production cost with the use of silica nanoparticles whereas comparison on a fixed annual crude oil processing basis results in a reduction in production cost of only $3.7 \%$. The significant reduction in the production cost, assuming a comparison on an equal plant capacity basis, is not due to the improvement in demulsification rather as a result of the higher throughput of processed crude oil due to the reduction in the time of treatment.

\section{Acknowledgments}

The authors are grateful for the financial support from the Sudanese Ministry of Higher Education and Scientific Research.

\section{REFERENCES}

1. Ali, A. A., Mustafa, M. A. \& Yassin, K. E. 2018. A techno-economic evaluation of bio-oil co-processing within a petroleum refinery. Biofuels, 1-9.

2. Gandomkar, G., Bekhradinassab, E., Sabbaghi, S. \& Zerafat, M. 2016. Improvement of chemical demulsifier performance using silica nanoparticles. World Academy of Science, Engineering and Technology, International Journal of Chemical, Molecular, Nuclear, Materials and Metallurgical Engineering, 9, 585-588. 
3. Hassan, S. A., Abdalla, B. K. \& Mustafa, M. A. 2019. Addition of silica nano-particles for the enhancement of crude oil demulsification process. Petroleum Science and Technology, 37, 1603-1611.

4. Kokal, S. L. 2005. Crude oil emulsions: A state-of-the-art review. SPE Production \& facilities, 20, 5-13.

5. Milligan D, M. J. 2019. Matches' engineering to chemical energy manufacturing metallurgical industries [Online]. Available: http://www.matche.com [Accessed 2 July 2019].

6. Toweler, G. \& Sinnott, R. 2009. Chemical engineering design: principles, practice and economics of plant and process design, Elsevier. 